\title{
Psychiatric Difficulties in Siblings of Handicapped Children
}

\author{
ELVA POZNANSKI, M.D.*
}

$T_{1}$ HE handicapped child, in our culture, is the focus of much attention and the community increasingly provides specialized services for him. Intractibility of his problem often taxes the pediatrician's skill and knowledge. In his home the extra time and attention the child requires may burden the family, particularly his mother, such that it interferes profoundly with normal family activities. The underlying effects which this emphasis may have upon brothers and sisters often are unrecognized or neglected, both by the parents and the family pediatrician.

\section{Illustrative Case Histories}

\section{Case 1. Brother with Congenital Heart Defect}

Tommy was referred for psychiatric problems at age seven. He was a charming, overweight boy, who consistently demonstrated attention-seeking behavior, both verbally and behaviorally. He poked and searched through the office in a fash. ion generally seen in much younger children. His parents were concerned because he was not doing well in school and felt that Tommy was "hard to reach." They were frustrated in that their discipline of him seemed ineffective. In school, Tommy was underachieving, doing work that was inconsistent and incomplete.

Tommy's brother, Tim, 15 months younger, had a congenital heare defect which necessitated

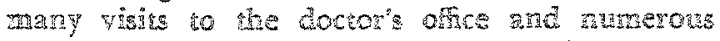
hospicalizations. During Tim's early life his activities were limited and he spent one year in bed. Twice, Tim went into heart failure and was rushed to the hospital by his panicked mother. The father was uninvolved with both children. The mother felt overburdened, caring both for a preschooler and a child who was chronically ill

- Instructor, Department of Psychiatry, University of Michigan Medical School, Anu Arbor, Nich. 48104.
Because handicaps are long-term problems, they can affect the emotional growth and development of the other children in the household. Child psychiatrists see more siblings of handicapped children than handicapped children themselves.

and likely to die. Out of this emotional turmoil and the nature of his illness a close bond developed between Tim and his mother. Tommy was left emotionally neglected, and it was implicd, "Since you are healthy, you should behave better. You don't need as much attention." A preschooler could not tolerate or comprehend this sort of message.

At age three, Tim had successful open-heart surgery. Tommy was four and one-half years old at the time of Tim's surgery. He became destructive during the period his brother was hospitalized. After surgery, the same pattern of relationships persisted despite correction of Tim's incapacity, i.e., Tim continued to have a fairly good relationship with his mother and Tommy still tried to get attention by a whole gamut of attention-seeking misbehavior. This gained him irritation instead of affection from his parents. Tommy felt more alienated than ever, but was unable to cope in a more satisfactory fashion. Tommy's hostility for his brother was open, "I wish he had died when he had his heart operation." Jealousy over the "b0 million presents" his brother received while in the hospital also was apparent. Tommy's emotional reaccions to the heart surgery, wo and one-half years later, were so evicient that one suspected Tommy was talking about not only past events, but the present as well-namely, the favored position his brother still enjoyed.

Some problems might have occurred in this family without Tim's heart defect. The handicap, however, did trigger the mother's intense involvement with Tim at the expense of Tommy. Tommy's position was mainly that of an extra burden during his preschool years. 


\section{PSYCHIATRIC DIFFICULTIES IN SIBLINGS OF HANDICAPPED CHILDREN}

Psychiatric contacts with this family were inconsistent. A recrudescence of Tommy's negativistic and difficult behavior at home or school would cause them to keep several psychiatric appointments, followed by long absences. The father and mother had a number of marital problems which neither felt inclined to face. During the time Tommy was seen, his personality pattern remained essentially unchanged.

Having a brother with a congenital heart defect certainly contributed to Tommy's psychologic problems. The family's relationship with their pediatrician was positive. One could speculate that early recognition might have been the best therapy.

\section{Case 2. A Mentally-retarded Sisier}

Jane was referred to a psychiatrist at age 13 because of persistent insomnia. Jane was a plain, mildly obese, somewhat shy teenager, who had meager peer relationships. Her relationship with her mother was tenuous and dependent. This state of affairs obviously had developed over many years and adolescence had merely activated the problem.

Jane's younger sister, Darlene, age 11, was severely mentally retarded and recently had been placed in a private institution. The long time it took to place this child reflected the mother's tre. mendous sense of guilt. Through the childhood years the mother was involved heavily with Darlene, who needed extra time and training each step of the way. The mother could not allow herself to be angry at Darlene "who couldn't help it," yet she made unrealistic demands of Jane. It was almost as if Jane was expected to achieve both for herself and her retarded sister.

When Jane couldn't sleep, she demanded that her mother stay up with her, perhaps in retaliation. In addition to her mother's overinvolvement with the retarded sister, Jane suffered much teasing from other children about her sister. Like her mother, she had great difficulty expressing her feelings about this and spoke in a pseudosophisticated manner, denying her own angry feelings towards her sister.

Jane's mother appeared to have the warmth and strength to provide her with healthy mothering. It seemed that, without the complications presented by the retarded child, Jane and her mocher mould have a relativaly nomai relation. ship.

In psychiatric therapy Jane faced some of her inner feelings and achieved a more independent and secure relationship with her mother. The mother, on her own, sought psychiatric help, which aided the progress of her daughter's therapy. A truly final outcome can be assessed only after the termination of Jane's adolescence.

\section{Discussion}

A handicapped child in the home, whether mentally retarded, congenitally defective or chronically ill, always throws an emotional strain upon the family. The handicapped child is usually more difficult to raise; he demands more time, attention and money than a normal child. Yet, in return, the parents do not have the usual gratifications of seeing one of their offspring growing and competing in the world with all assets available. Families react in many ways. Feelings of disappointment, frustration and resentment invariably are aroused. Their resolution or adaptation to such a situation is crucial to all family members.

Most pediarricians know of families in which these feelings are shown directly to the handicapped child, who has become covertly or openly rejected. Another "solu. tion" is to refuse to acknowledge the child's actual medical condition. With either of these reactions, the pediatrician tends to be frustrated and irritated with the parents.

A less obvious way in which parents sometimes cope with their negative feelings about a handicapped child is to express them toward another child in the family. This reaction is somewhat akin to the man who comes home from work and kicks the dog when he's angry at the boss. The parents may hold back some, or all, of their negative feelings from the handicapped child and consistently "take it out" on one of the healthy siblings.

Mothers especially have a tendency to feel responsible for and even guilty about any defect in a child of theirs. They take it very personally. The sense of guilt may motivate unrealistic attempts to "make it up" to the affected child. The increased needs of the handicapped child stimulate matemal needs to protect and care, and gemeraly irrensify the bond between them. In many families with a handicapped child, an alliance seems to develop between mother and this child, while the father allies himself with the rest of the children. A psychologic reaction such as this assumes clinical importance when siblings of the handicapped child demonstrate 


\section{POZNANSKI}

behavioral reactions as a consequence of emotional neglect.

\section{Prevention}

The pediatrician is in a unique position to discover whether the emotional needs of all the children in such a family are being met. Giving the mother the opportunity to talk about her own guilt feelings can in itself be highly therapeutic.

Spontaneous comments from the mother on how the rest of the children react to the affected child's handicap and problems is a healthy sign. When there are no such comments forthcoming, the pediatrician may inquire about the other children's reactions. If the mothers' answer demonstrates an awareness of all the children's needs, fine and good. If the question surprises her, there may be trouble brewing. Tactful questioning by the pediatrician may help him assess whether the mother's care of the handicapped child is realistic or overzealous. Simply speaking of the needs of all the children may stimulate the mother to take stock of the family situation.

The presence of a handicapped child in a family does stress the total family adjustment. The relationships of the mother with her other children often become distorted, at times severely, because of the extra time and attention the handicapped child requires. Understandably, the other children tend to interpret this as meaning that they are less favored and loved. For parents who have other problems, such as marital disharmony or personality difficulties, or lack sensitivity to their children's emotional needs, the simple presence of the handicapped child may incite or aggravate unhealthy relationships among family members.

The pediatrician should be alert to this potential source of difficulty in these families. He should try to ameliorate the situation by counselling the parents or referring them to other mental health resources.
(Book Reviews continued from page 203)

New Haven, and the Children's Center in Syracuse.

The implications are limitless. "High risk" infants (that is, social high risk) born into situations of poverty and deprivation, are familiar to all pediatricians. Communities, both professional and lay, must reach out and provide assistance. Health and welfare agencies must unite their efforts to provide guidance and homemaking help for mothers when the infants are smaill, and optimal daycare programs when the youngsters are older. The question, as Reginald Lurie concludes, is not "Can we afford these services?" Rather, our current knowledge of the relationships of economic and psychologic deprivation in infancy to later adult malfunction, suggests that we cannot afford not to provide these services.

This book is readable and timely. All pediatricians, and Head Start Consultants in particular,

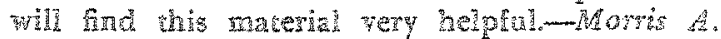
Wessel, M.D. New Haven, Conr.

\section{Schizophrenia in Children}

J. Louise Despert, M.D. New York, Robert Brunner, Inc., 1968.215 pp. $\$ 6.95$.

This book is a collection of papers written by Louise Despert, M.D., and the presentations date back to about 1937 . Certainly Dr. Despert has been one of the more active workers in the area of childhood psychosis and the various chapters form a historical review of hers as well as others thinking in regard to this complex syndrome. She deals with such things as thinking in schizophrenic children, treatment of these youngsters, early recognition of the condition, delusional and hallucinatory experiences in children, and the genesis of autistic behavior. One chapter is devoted to the differential diagnosis between obsessive compulsive neurosis and schizophrenia; another looks into the diagnostic criteria of schizophrenic illness and psychoses of early infancy and early childhood. At the end is a later chapter written in the 1950's on the treatment of childhood schizophrenia.

As Dr. Leo Kanner writes in the foreword, it is useful to have Dr. Despert's work brought together in one book so the reader can review some of the pas thinking about these disorders. The book should be interesting reading for the pediatricitan who wants to know more about this complex dis. ease. It offers him tar more theory than practical knowledge, and may accordingly be disappointing. It should be remembered that we still do not know nearly all we should about the etiology or the treatment of this condition. - Stutart $M$. Finch, M.D., University of Michigan Medical School.

(Continued on page 242) 